Marketing in Asia Group

\title{
Mobile Internet Adoption in Malaysian Suburbs: The Moderating Effect of Gender
}

\author{
Soon-Ming Wong \\ Faculty of Economics and Business, Universiti Malaysia Sarawak, Sarawak, \\ Malaysia
}

\section{Choi-Meng Leong}

Affiliation (Department, University, State/Province, Country)

Faculty of Business and Information Science, UCSI University, Sarawak, Malaysia

\section{Chin-Hong Puah}

UNIMAS Business School, Universiti Malaysia Sarawak, Sarawak, Malaysia

Faculty of Economics and Business, Universiti Malaysia Sarawak, Sarawak, Malaysia

\begin{abstract}
This study utilizes the Unified Theory of Acceptance and Use of Technology (UTAUT2) to identify the factors affecting the adoption and use of mobile Internet in the Malaysian suburban context. Seven key constructs comprise performance expectancy, effort expectancy, social influence, facilitating conditions, hedonic motivation, price value and habit are used for the investigation. Gender is hypothesized to moderate the effects of the factors on behavioural intention and use behaviour. A self-administered questionnaire was adopted and a total of 403 usable responses were employed for the analysis, using partial least squares structural equation modelling. The findings of the analysis revealed that all key constructs (except social influence) affect mobile Internet adoption among suburban users. Gender was found to moderate the relationships among effort expectancy, social influence, hedonic motivation, price value, habit, and behavioural intention. Importance-performance map analysis for gender also demonstrated that awareness needs to be created for all factors (except price value) with slightly different weights for all factors. These findings provide crucial implications for mobile Internet service providers to formulate their strategies for suburban users. This study represents one of the few attempts to reveal the behavioural intention and use behaviour for mobile Internet among Malaysian suburban users by taking gender into consideration.
\end{abstract}

Keywords: UTAUT2; Mobile Internet Adoption; Mobile Internet Use Behaviour; Gender

Publication Details: Received 13 Aug 2019; Revised 1 Dec 2019; Accepted 10 Dec 2019 


\section{Introduction}

The world has changed dramatically since the emergence of the Internet in the 1980s. Over the past few decades, technology development and the Internet's growth have changed the way people shop, socialize, communicate with each other, obtain entertainment content, as well as gather information and news (Evan, 2013; Susan, 2013). Backed by the entire telecommunication industry as well as combining two of the most outstanding recent innovations (the Internet and mobile devices such as smart phones), the mobile Internet has become one of the most popular services provided to consumers worldwide and is positioned to emerge ahead of fixed Internet (Jiang, 2009).

There has been an explosive growth in the number of mobile Internet connections. Also, the increase in capability of smartphones alongside increased affordability have led to more access to data intensive applications and services. This has in turn led to continuing mobile data traffic growth. This strong growth of mobile data traffic requires more mobile bandwidth as well as spectrum resources, which are in fixed or finite supply, forcing the necessity for spectrum efficiency increments to accommodate demand growth. Hence, over the past five years, mobile service operators have made significant investments in infrastructure, facilitating an ongoing migration of technology to higher speed networks. This can be shown with huge capital expenditure (capex) laid for infrastructure increments and improvements to support growing bandwidth demands, mobile broadband network coverage as well as deployment. The return on investments very much depends on the numbers of mobile Internet users. Thus, it is critical for mobile service operators to understand the behaviour of the users in order to improve market share.

In Malaysia, Internet users in 2018 were $87.4 \%$ and the smartphone was the most common device used to access the Internet with a rate of $93.1 \%$ based on the Internet Users Survey 2018 conducted by the Malaysian Communications and Multimedia Commission. The smartphone penetration rate as a share of the population was $49 \%$ in 2017 (Statista, 2019). On the other hand, the broadband subscription and penetration rate in the same year was $37.85 \%$ (Malaysian Communications and Multimedia Commission, 2018), which lagged behind the smartphone penetration rate.

Most of the unconnected populations are those with lower incomes and high levels of illiteracy from suburban or rural areas, which creates barriers to the adoption of the mobile Internet. Therefore, operators and other mobile ecosystem players such as smart device manufacturers as well as governments and regulators all play a role in tackling these barriers to improve literacy, reach and affordability of mobile Internet (GSM Association, 2015).

Suburban areas are combined with metropolitan cities to form metropolitan areas with a population of more than one million (Rofiei, Tawil, Kosman \& Che-Ani, 2016). High costs incurred in building infrastructure contributes to the lower level of broadband accessibility in suburban and rural areas (Performance Management and Delivery Unit, 2010). However, suburbs undergo rapid urbanization, which witnesses more new developments taking place (Sahari, 2015). Internet connectivity could soon be listed under utilities in Malaysia (Ariff, 2019). Due to the importance of the 
Internet in one's daily life, suburban areas could be where Internet service providers underserve a growing population. Accessibility to the Internet is critical to promote the acquisition of new knowledge and skills as well as providing alternative sources of income generation in suburban and rural areas (Economic Planning Unit, 2015). In addition, the digital economy contributed 18.5 percent to the gross domestic product in Malaysia in 2018 with Internet activities such as e-commerce transactions recording an annual growth of 6 percent in 2017 (The Sun Daily, 2019). Suburban areas could benefit from the digital economy with proper Internet access. Thus, it is challenging to match the demand for Internet accessibility in suburbs. Alternatively, the mobile Internet service providers can consider improving network coverage to provide mobile Internet service in addition to broadband. Therefore, it will be vital to reveal user behaviour in mobile Internet adoption in suburban areas. The information will be critical to mobile service operators for market share improvement, as well as being important to government for policy design and broadband project development. This study aims to bridge the gap between behaviour study and broadband adoption by identifying the predictors of mobile Internet adoption among suburban users in Malaysia.

Internet Users Survey 2018 revealed that males have a higher Internet adoption rate (59\%) compared to females (41\%). Compared to men, women tend to earn less and hold lower-paid jobs (Cahill \& Ryan, 2019). This trend shows that women spend twice as much time as men carrying out unpaid house work, taking care of family members, cleaning, and meal preparation. This has restrained them from carrying out activities based on income generation, education and leisure (Cahill \& Ryan, 2019). Thus, it will be interesting to determine whether gender moderates Internet adoption in the suburban areas in Malaysia, as males and females operate in different societal backgrounds. Consequently, this study aims to address the factors affecting mobile Internet adoption and use behaviour among the suburban users as well as to identify the gender effect among the factors, mobile Internet adoption and use behaviour.

This study is organized as follows: (1) introduction to reveal the significance of conducting this study; (2) literature review to develop the research framework and hypotheses of this study; (3) research methods to explain techniques and procedures used to conduct this study; (4) results to reveal the findings; (5) discussion to further explain the results obtained; (6) managerial implications to provide recommendations to related parties, and finally (7) further research directions.

\section{Literature Review}

Various theories and models apply different investigative approaches to the process of acceptance with some similarities existing in common models (Madara, 2013). Many models are developed by supplementing the existing models or by combining multiple models such as the Technology Acceptance Model (TAM), the Motivational Model and others (Venkatesh et al., 2003). Information System (IS) researchers face dilemma in selecting an appropriate model among a huge range of choices, as choosing one model will ignore the contribution of the alternative models (Venkatesh et al., 2003). Thus, a synthesis is needed to achieve a unified view of technology acceptance among users (Al-Qeisi, 2009). As a result, the Unified Theory of 
Acceptance and Use of Technology (UTAUT) was introduced, together with its later extension, the Unified Theory of Acceptance and Use of Technology 2 (UTAUT2).

UTAUT comprises four key concepts, namely performance expectancy, effect expectancy, social influence and facilitating condition (Venkatesh et al., 2003). UTAUT2 was then evolved from UTAUT, where hedonic motivation, price value and habit were added. These variables had demonstrated critical roles in explaining user intention towards new technologies (Arenas-Gaitán, Peral-Peral \& Ramón-Jerónimo, 2015).

\section{Behavioural Intention}

Consumer behavioural intention is the subjective judgment on how a person will perform in the future and it establishes a linkage between the person and the adopted product or service (Kim \& Littrell, 1999; Madden et al., 1992). UTAUT2 is used to investigate the consumer behavioural intention in this study for several reasons. Besides fulfilling global and integrative approaches in explaining technology acceptance and use, UTAUT2 can also explain the consumption contexts well via a specially designed novel theory (Herrero, San Martín \& García de los Salmones, 2017). The UTAUT2 has been shown to provide an excellent framework to identify the determinants of technology acceptance intentions and adoption in the literature (Venkatesh, 2012; Madara, 2013; Huang \& Kao, 2015; Jorge et al., 2015; Gupta, Dogra \& George, 2018; Sivathanu, 2019). Thus, UTAUT2 is used for the investigation of mobile Internet adoption among suburban residents in Malaysia. There are seven key determinants of behavioural intention under UTAUT2: Performance expectancy, effort expectancy, social influence, facilitating conditions, hedonic motivation, price value and habit.

\section{Performance Expectancy}

This determinant explains the extent to which new technology usage or adoption can benefit consumers in accomplishing specific activities (Venketesh et al., 2012). It is one of the most influential determinants for intention to adopt (Dwivedi et al., 2017a; 2017b). This construct consists of five criteria: extrinsic motivation, perceived usefulness, outcome expectations, job fit and relative advantage. Extrinsic motivation refers to people's perceptions on whether to carry out an activity when such an activity is recognized as an instrument to achieve different valued outcomes to the activity itself (Teo et al., 1999; Chong, 2013). On the other hand, perceived usefulness is the extent to which a person believes that new technology can improve his or her job performance (Davis, 1989). Next, outcome expectations are the anticipated consequences of a person's behaviour, in which the expectancies focus on the outcome value and are subjective to different individuals (Bandura, 1986). Job fit can be explained as how new technology capabilities will raise people's job performance (Thompson et al., 1991; Jeng \& Tzeng, 2012). Lastly, relative advantage is the benefit of a new technology or a technology product adoption over the costs (Rogers, 1962). Based on Oliver's (1980) Expectation Confirmation Theory (ECT), when the expectation of a user is confirmed, satisfaction will follow. In the context of availability of various task environments, performance expectancy affects intention to use (Baptista \& Oliveira, 2015). Therefore, performance expectancy is posited to affect the behavioural intention to use mobile Internet. It is one of the key factors affecting technology adoption (Duarte \& Pinho, 2019). 


\section{Effort Expectancy}

Effort expectancy is the extent to which ease of use is associated with a new technology or technology product usage (Venketesh et al., 2012). In the technology adoption context, the performance and the effort expectancies are two major salient predictors to analyse technology behavioural intention and usage behaviour (Davis, 1989; Thompson et al., 1991; Kijsanayotin et al., 2009; Casey and Wilson, 2012).

Effort expectancy in the mobile Internet context is the perceived difficulty in using the services. Less effort required will strengthen the intention to use a particular technology (Sivathanu, 2019). Mobile terminals, especially smart phones, are constrained by inconvenient input as well as smaller screens for data entry and information searching. Users will not be satisfied if greater effort is required to learn or become skilful with the mobile Internet. Thus, satisfaction will be affected by the amount of effort required. The perceived ease of use and effort expectancy has similar effects on user satisfaction and continued usage (Zhou, 2011; Madara, 2013), as perceived ease of use is a critical antecedent of UTAUT2 (Dwivedi et al., 2016). Effort expectancy is another key factor alongside performance expectancy that affects mobile technology adoption (Duarte \& Pinho, 2019). Therefore, effort expectancy is expected to influence behavioural intention to use the mobile Internet.

\section{Social Influence}

Social factors can influence a users' decision-making process concerning adopting innovative technology (Roger, 1962). The social norms come with two different influences, which are informational and normative. Informational influence refers to one's information gathering from other people that influences decisions, while normative influence is the conformation of a user to other people's expectations in order to gain a reward or to avoid a punishment (Hsu and Lu, 2004). Therefore, social influence can exist: either individuals are persuaded to engage due to pressure from friends and family, or they desire to impress others (Shaw \& Sergueeva, 2019).

In the case of mobile Internet technology services, social influence indicates the referees' opinion effect on the behaviour of individual users where compliance with important referee's opinions may be influential. Thus, the more important the recommendations of others are to a user, the more he or she will take up and adopt mobile Internet. Zhou (2011) and Madara (2013) found that mobile data service continuance intentions can be significantly affected by social influence in the sense that social influence is positively related to intention to use (Moon \& Hwang, 2016).

\section{Facilitating Conditions}

Facilitation environment varies significantly between each consumer across technology generations, mobile devices, and application vendors in the consumer context. In addition, different phones used by consumers may come with different levels of data transfer rates and capabilities to facilitate mobile Internet experiences which may consequently result in different levels of mobile Internet adoption too. In other words, facilitating conditions are the knowledge and resources necessary for mobile Internet usage that the users possess (Zhou, 2011; Madara, 2013). In addition, they also need the necessary knowledge to operate the mobile Internet. Thus, 
facilitating conditions can be in the form of guidance, help and training provided (Sivathanu, 2019). If the users do not possess such knowledge and resources, they may not continue to use mobile Internet. For instance, the ease of use of the technology in mobile health contributes to its acceptance (Duarte \& Pinho, 2019). Therefore, the facilitating condition of UTAUT2, which is based on the general model of The Theory of Planned Behaviour (TPB), is linked to both behavioural intention and actual behaviour in the consumer context.

\section{Hedonic Motivation}

Hedonic motivation plays a key role in determining technology acceptance and use (Brown \& Venkatesh, 2005). The emphasis on technology for organizational users has moved to consumers, which is from extrinsic motivation to intrinsic motivation (Tamilmani, Rana, Prakasam \& Dwivedi, 2019). It is referred to as the willingness and motivation to use a technology as a result of the pleasure gained from aesthetic and emotional feelings such as love and joy. From the hedonic perspective of individual behaviours, hedonic motivation is linked to the psychological and emotive experiences of an individual, which can be initiated by both cognitive states and individual traits (Magni et al., 2010).

This is an approach to cognitively attracting users to online platforms by using the underlying intrinsic value to drive the outcome (Merhi, Hone \& Tarhini, 2019). The positive hedonic influence from the pleasure will stimulate intention and use. For instance, if a user found great enjoyment and fun in accessing mobile Internet on a smart phone to play online games on-the-go, the intention to use and adopt such technology will be strongly motivated. Therefore, hedonic motivation significantly influences the intention to use (Ravangard, Kazemi, Zaker Abbasali, Sharifian, \& Monem, 2017). Thus, hedonic motivation can be a strong predictor of mobile Internet adoption.

\section{Price Value}

In the UTAUT model, the consumer technology use setting is significantly different from the organizational use setting. The monetary cost of technology usage normally needs to be borne by consumers, which is not the case for employees. The price comprises device and data costs as well as service charges (Chopdar, Korfiatis, Sivakumar \& Lytras, 2018). This monetary cost and pricing structure can significantly impact technology adoption among consumers. On the other hand, the perceived value of products or services in marketing research is normally determined by the conceptualized monetary cost or price together with the product or service quality (Zeithaml, 1988).

In the marketing context, two price value perspectives are included, namely the monetary costs and the non-monetary costs. The monetary costs refer to the value being identified in contrast to the paid price (Petrick, 2002), while the non-monetary costs are the value being identified in return for the expended costs like effort and time (Boksberger \& Melsen, 2011). The positive impact of price value is derived when the benefits of technology usage are perceived to be greater than the monetary cost (Chopdar, Korfiatis, Sivakumar \& Lytras, 2018). Subsequently, a positive impact on intention is expected for price value. Hence, price value can serve as a behavioural 
intention predictor for mobile Internet adoption. Price value also shows a significant impact on intention to use (Ravangard et al., 2017).

\section{Habit}

Habit is the extent to which people will carry out automatically certain behaviours due to learning (Limayem et al., 2007). Habit will be created due to the frequent use of a technology (Merhi et al., 2019). In addition, certain habitual behaviours can also be developed due to the length of time a person owns a phone or other applications (Shaw \& Sergueeva, 2019). Although quite similarly conceptualized, two distinctive ways have operationalized habit. Kim and Malhotra (2005) viewed habit as prior behaviour while Limayem et al. (2007) considered habit as the extent to which behaviour is believed by an individual to be automatic.

This brings three criteria into habit, namely past behaviour, reflex behaviour and individual experience. Past behaviour is the prior behaviour of users (Kim and Molhatra, 2005). Reflex behaviour is the behaviour customs or sequences of users which constitute parts of regular daily life, while individual experience is stable norms, routines and habits in technology product usage which are established from accumulated experiences (Limayem et al., 2007).

The need for coordination, discussions or effortful decision making is also reduced by such experiences. For instance, after using social media applications on mobile devices during commuting for an extended period of time, a positive view toward mobile Internet technology may be developed by a consumer and this also applies to behavioural intention where such intention will impact the consumer's conscious mind and is stored. When the consumer later enters a taxi or a car, positive views and intentions will be triggered spontaneously by the environment or context to result in the behaviour (e.g., take out the mobile device and start using social media applications). With such reasoning, stronger habits will trigger a stored intention that will subsequently influence behaviour. In line with this, many past studies of habitual intentions as well as habitual usage behaviours have verified and confirmed that habit can be a strong technology usage predictor in promoting changes in behaviour (Kim et al., 2007; Webb et al. 2009; Wang and Wang, 2010; Venkatesh et al., 2012). Habit also shows a direct impact on technology acceptance and use (Macedo, 2017).

\section{Use Behaviour}

According to Ajzen and Fishbein (1975), if a person intends to perform a behaviour, then it is likely that the person will do it or in other words, behavioural intention will lead to use behaviour. Therefore, when consumers have high mobile Internet adoption levels, it is likely that such technology use behaviour will be triggered. Use behaviour is the frequency of usage of information technology (Ramírez-Correa, RondánCataluña, Arenas-Gaitán \& Martín-Velicia, 2019).

Besides, more opportunities will be given to consumers with increasing experience to strengthen their habit because they have more time to process cues and to carry out the associated behaviour (Kim and Malhotra, 2005). In addition, routine behaviour will also be automated and guided further by associated cues with increasing 
experience (Jasperson et al., 2005). As a result, the behavioural intention effect on technology use will reduce when more experience is gained.

\section{Gender Effect}

The impact of gender is different on seven core UTAUT2 intention and usage determinants. For instance, the gender effect on effort expectancy, social influence, facilitating conditions and price value are stronger for women while the effect on performance expectancy, hedonic motivation and habit is greater for men (Venkatesh et al., 2012; Madara, 2013). In another study, Ameen and Willis (2019) revealed that gender differences existed in perceived relative advantage (performance expectancy) and habit. Inconsistencies in the findings provide room for investigation regarding the gender effect on mobile Internet adoption among suburban users in Malaysia.

Some hypotheses are developed to posit the relationships among the variables as follows and the framework developed is shown in Figure 1.

H1 Performance expectation is positively related to mobile Internet adoption.

H2 Effort expectancy is positively related to mobile Internet adoption.

H3 Social influence is positively related to mobile Internet adoption.

H4 Facilitating conditions are positively related to mobile Internet adoption.

H5 Hedonic motivation is positively related to mobile Internet adoption.

H6 Price value is positively related to mobile Internet adoption.

H7 Habit is positively related to mobile Internet adoption.

H8 Mobile Internet adoption can significantly affect the use behaviour of mobile Internet.

H9a Gender moderates the relationships between performance expectancy and mobile Internet adoption.

H9b Gender moderates the relationships between effort expectancy and mobile Internet adoption.

H9c Gender moderates the relationships between social influence and mobile Internet adoption.

H9d Gender moderates the relationships between facilitating conditions and mobile Internet adoption.

H9e Gender moderates the relationships between hedonic motivation and mobile Internet adoption. 
H9f Gender moderates the relationships between price value and mobile Internet adoption.

H9g Gender moderates the relationships between habit influences and mobile Internet adoption.

H9h Gender moderates the relationship between mobile Internet adoption and use behaviour of mobile Internet.

Figure 1: Research Framework

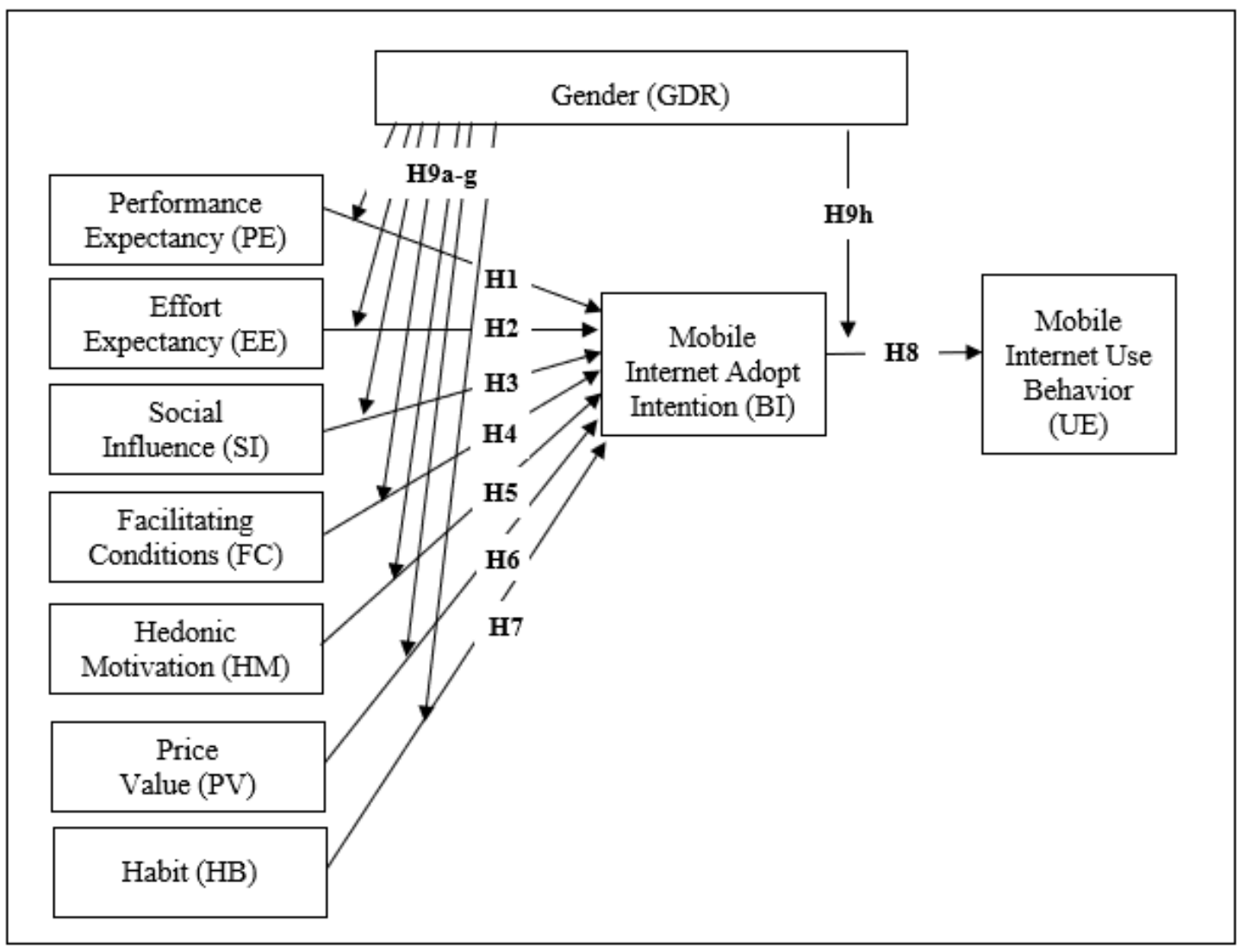

\section{Research Methods}

The target respondents for this study are mobile network service subscribers in suburban areas in Malaysia, and thus purposive sampling was adopted in this study. A survey via a web-based questionnaire is used to gather data in this study. The questionnaire was bi-lingual, namely English and Malay, to reduce sampling error and to enhance generalizability of the findings. The web-based questionnaire was administered via a trusted email database and the link for the web-based questionnaire was emailed to the selected respondents. These respondents were informed of the survey's purpose and the confidentiality of their input. The questionnaire was also estimated to take about 7 to 10 minutes for each respondent to complete. G*Power was used to determine the sample size using 0.15 medium effect size of f2, significance level of 0.05 and power of 0.80 . The minimum sample size was 139.450 completed questionnaires were collected over one month and each of the 
questionnaires was screened to exclude copies of questionnaires with serious missing data and straight-lining patterns. 403 questionnaires were retained for estimation after the data screening process. The statistical remedy was used to address potential common method bias. Thus, the Harman single-factor test was performed. The total variance explained for a single factor was $48.4 \%$, which is less than the threshold value of $50 \%$.

All the measuring scales in the questionnaire were adapted from the original UTAUT2 work by Venkatesh et al. (2012). The questionnaire was divided into two parts. Part A included three sections, with the first designed to examine the seven core determinants of UTAUT2 (i.e., PE, EE, SI, FC, HM, PV, and HB) that affect consumer mobile Internet adoption intention and use behaviour. Each item in this section consisted of four testing statements with a seven-point Likert scale (endpoint anchored) being strongly disagree $(=1)$ to strongly agree $(=7)$. The second section also consisted of four statements to test the likelihood of respondents' behavioural intentions to adopt mobile Internet with a seven-point scale ranging from very unlikely $(=1)$ to very likely $(=7)$. The third section measured the variety and frequency of mobile Internet use based on 6 high popularity Internet activities in Malaysian suburban areas. The anchors of the seven-point scale which ranged from never $(=1)$ to many times per day $(=7)$ were used. Part B of the questionnaire mainly focused on the respondent's demographic background including gender, age, highest education level, current area of employment and monthly gross income. The data collected was estimated using partial least squares structural equation modelling (PLS-SEM) to identify the relationships between all determinants and mobile Internet adoption intention as well as the moderating effect of gender on the relationships. The gender effect is further analysed using importance-performance map analysis (IPMA) to provide directions on the strategies that can be implemented by mobile Internet service providers.

\section{Results}

Table 1: Demographic Background of Respondents

\begin{tabular}{llrr}
\hline $\begin{array}{l}\text { Demographic } \\
\text { Variables }\end{array}$ & Category & Frequency & Percent \\
\hline Gender & Male & 195 & 48.4 \\
& Female & 208 & 51.6 \\
\hline Age & $21-34$ & 181 & 44.9 \\
& $35-49$ & 171 & 42.4 \\
& $50-64$ & 40 & 9.9 \\
& 65 and above & 11 & 2.7 \\
\hline Highest Education & Primary Level & 1 & 0.2 \\
Level & Secondary Level & 20 & 5.0 \\
& College/Polytechnic & 7 & 1.7 \\
& Bachelor's Degree & 228 & 56.6 \\
& Master's Degree & 142 & 35.2 \\
& Doctoral Degree & 5 & 1.2 \\
\hline
\end{tabular}




\begin{tabular}{llrr}
\hline Current Area of & Homemaker & 1 & 0.2 \\
Employment & Retiree & 15 & 3.7 \\
& Student & 19 & 4.7 \\
Unemployed & 3 & 0.7 \\
Accountancy & 26 & 6.5 \\
Agriculture, Forestry, or Fishery & 10 & 2.5 \\
Architecture & 5 & 1.2 \\
Arts, Entertainment, or Recreation & 7 & 1.7 \\
Broadcasting & 1 & 0.2 \\
Education & 25 & 6.2 \\
Engineering & 23 & 5.7 \\
Finance and Insurance & 32 & 7.9 \\
Government and Public & 22 & 5.5 \\
Administration & & \\
Health Care and Social Assistance & 19 & 4.7 \\
Hotel and Food Services & 18 & 4.5 \\
Information Technology & 38 & 9.4 \\
Legal Services & 7 & 1.7 \\
Manufacturing & 35 & 8.7 \\
Publishing & 4 & 1.0 \\
Real Estate, Rental, or Leasing & 1 & 0.2 \\
Retail & 16 & 4.0 \\
Telecommunications & 3 & 0.7 \\
Transportation and Warehousing & 15 & 3.7 \\
Utilities & 7 & 1.7 \\
Other & 51 & 12.7 \\
\hline Dependents & 25 & 6.2 \\
Less than RM2,000 & 24 & 6.0 \\
RM2,000 - RM3,999 & 153 & 38.0 \\
RM4,000 - RM5,999 & 101 & 25.1 \\
RM6,000 - RM7,999 & 64 & 15.9 \\
RM8,000 - RM9,999 & 26 & 6.5 \\
RM10,000 and above & 10 & 2.5 \\
\hline & & \\
\hline
\end{tabular}

\section{Demographic Background}

Table 1 shows that there were more female respondents (51.6 percent) than male respondents (48.4 percent). Many of the respondents were aged from 21 years to 34 years (44.9 percent). The majority of the respondents were bachelor's degree holders (56.6 percent). In addition, 38 respondents worked in information technology. The most common monthly gross income range among the respondents was RM2,000 to RM3,999 (38.0 percent). 


\section{Assessment of Measurement Model}

Assessment of the measurement model includes the investigation of the reliability and validity of the constructs. Table 2 presents the results of the measurement model. The results show that all loading values are greater than 0.708 except UE4 and UE6. However, the average variance extracted (AVE) of all constructs is greater than 0.5 and thus fit for estimation.

Table 2: Measurement Model

\begin{tabular}{|c|c|c|c|c|}
\hline Variable & Item & Loading & $\begin{array}{l}\text { Composite } \\
\text { Reliability }\end{array}$ & $\begin{array}{l}\text { Average Variance } \\
\text { Extracted (AVE) }\end{array}$ \\
\hline \multirow[t]{4}{*}{ Performance Expectancy } & PE1 & 0.928 & 0.956 & 0.844 \\
\hline & PE2 & 0.910 & & \\
\hline & PE3 & 0.924 & & \\
\hline & PE4 & 0.913 & & \\
\hline \multirow[t]{4}{*}{ Effort Expectancy } & EE1 & 0.959 & 0.976 & 0.912 \\
\hline & EE2 & 0.951 & & \\
\hline & EE3 & 0.956 & & \\
\hline & EE4 & 0.954 & & \\
\hline \multirow[t]{4}{*}{ Social Influence } & SI1 & 0.904 & 0.944 & 0.808 \\
\hline & SI2 & 0.922 & & \\
\hline & SI3 & 0.889 & & \\
\hline & SI4 & 0.878 & & \\
\hline \multirow[t]{4}{*}{ Facilitating Conditions } & $\mathrm{FC} 1$ & 0.915 & 0.955 & 0.841 \\
\hline & $\mathrm{FC} 2$ & 0.937 & & \\
\hline & $\mathrm{FC} 3$ & 0.939 & & \\
\hline & FC4 & 0.877 & & \\
\hline \multirow[t]{4}{*}{ Hedonic Motivation } & HM1 & 0.936 & 0.958 & 0.852 \\
\hline & HM2 & 0.935 & & \\
\hline & HM3 & 0.918 & & \\
\hline & HM4 & 0.903 & & \\
\hline \multirow[t]{4}{*}{ Price Value } & PV1 & 0.942 & 0.953 & 0.835 \\
\hline & PV2 & 0.933 & & \\
\hline & PV3 & 0.948 & & \\
\hline & PV4 & 0.826 & & \\
\hline \multirow[t]{4}{*}{ Habit } & HB1 & 0.944 & 0.972 & 0.897 \\
\hline & HB2 & 0.948 & & \\
\hline & HB3 & 0.945 & & \\
\hline & HB4 & 0.950 & & \\
\hline \multirow[t]{4}{*}{ Mobile Internet Adoption } & BI1 & 0.938 & 0.970 & 0.891 \\
\hline & $\mathrm{BI} 2$ & 0.943 & & \\
\hline & $\mathrm{BI} 3$ & 0.941 & & \\
\hline & $\mathrm{BI} 4$ & 0.953 & & \\
\hline \multirow[t]{4}{*}{ Use Behavior } & UE1 & 0.873 & 0.820 & 0.538 \\
\hline & UE3 & 0.760 & & \\
\hline & UE4 & 0.664 & & \\
\hline & UE6 & 0.607 & & \\
\hline
\end{tabular}


Discriminant validity is assessed by using Henseler's Heterotrait-Monotrait (HTMT) (2015) criterion. All values of the constructs fulfill the criterion at the threshold of HTMT.90 (see Table 3) and thus verify the discriminant validity.

Table 3: HTMT Criterion

\begin{tabular}{lccccccccc}
\hline & BI & EE & FC & HB & HM & PE & PV & SI & UE \\
\hline BI & & & & & & & & & \\
EE & 0.777 & & & & & & & \\
FC & 0.663 & 0.630 & & & & & & \\
HB & 0.831 & 0.646 & 0.569 & & & & & \\
HM & 0.721 & 0.587 & 0.554 & 0.637 & & & & & \\
PE & 0.825 & 0.678 & 0.573 & 0.682 & 0.683 & & & \\
PV & 0.521 & 0.357 & 0.404 & 0.398 & 0.356 & 0.449 & & \\
SI & 0.483 & 0.351 & 0.434 & 0.438 & 0.490 & 0.463 & 0.355 & & \\
UE & 0.868 & 0.776 & 0.675 & 0.745 & 0.555 & 0.710 & 0.476 & 0.450 & \\
\hline
\end{tabular}

\section{Assessment of Structural Model}

The assessment of the structural model is conducted to check for collinearity issues, the significance and relevance of the relationships, the level of the coefficient of determination $\left(R^{2}\right)$, the level of effect size $\left(f^{2}\right)$ and the predictive relevance $\left(Q^{2}\right)$. All the Variance Inflator Factor (VIF) values for all constructs are less than 5.0 (Hair et al., 2017) and thus do not posit collinearity issues (see Table 4).

The assessment of the path coefficient shows that all of the relationships between explanatory variables and mobile Internet adoption are significant $(\mathrm{H} 1, \beta=0.258, \mathrm{p}<$ $0.001 ; \mathrm{H} 2, \beta=0.221, \mathrm{p}<0.001 ; \mathrm{H} 4, \beta=0.064, \mathrm{p}<0.05 ; \mathrm{H} 5, \beta=0.099, \mathrm{p}<0.01 ; \mathrm{H} 6$, $\beta=0.123, \mathrm{p}<0.001 ; \mathrm{H} 7, \beta=0.347, \mathrm{p}<0.001)$ except social influence on mobile Internet adoption $(\mathrm{H} 3, \beta=0.019, \mathrm{p}>0.05)$. Thus, hypotheses from $\mathrm{H} 1$ to $\mathrm{H} 7$ are supported except H3. In addition, the relationship between mobile Internet adoption intention and mobile Internet use behaviour is also significant $(\mathrm{H} 8, \beta=0.775, \mathrm{p}<$ 0.001 ) and thus $\mathrm{H} 8$ is supported. For the moderating effect, gender moderates the relationship among effort expectancy $(\mathrm{H} 9 \mathrm{~b}, \beta=0.068, \mathrm{p}<0.05)$, social influence (H9c, $\beta=-0.05, p<0.05$ ), hedonic motivation (H9e, $\beta=0.072, p<0.05$ ), price value (H9f, $\beta=0.047, \mathrm{p}<0.05$ ), habit (H9g, $\beta=-0.084$, $\mathrm{p}<0.05$ ) and mobile Internet adoption. In addition, hypotheses $9 \mathrm{a}$ and $9 \mathrm{~d}$ are also not supported. Gender also does not moderate the relationship between mobile Internet adoption and use behaviour of mobile Internet and therefore hypothesis $9 \mathrm{~h}$ is not supported.

The assessment of $\mathrm{R}^{2}$ shows that the six constructs performance expectancy, effort expectancy, facilitating conditions, hedonic motivation, price value and habit describe $83.1 \%$ of the variation in mobile Internet adoption. On the other hand, mobile Internet adoption explains $60.1 \%$ of the variation in mobile Internet use behaviour. The $\mathrm{f}^{2}$ analysis indicates that the effect of performance expectancy is medium (Cohen, 1988) while effort expectancy, facilitating conditions, hedonic motivation, price value and habit have weak effects (Cohen, 1988) on mobile Internet adoption. Conversely, the effect of mobile Internet adoption on mobile Internet use behaviour is substantial. For moderating effects, gender shows a weak effect between the relationships of effort expectancy, social influence, hedonic motivation, price value, habit and mobile 
Internet adoption. The results of $\mathrm{Q}^{2}$ also imply that the determinants have predictive relevance for mobile Internet adoption intention as both values are greater than zero (Hair et al., 2017). However, the generated value of $\mathrm{Q}^{2}$ is based on single omitted and inputted data points, which combine in-sample and out-of-sample prediction. It does not evaluate the explanatory power of a model. Therefore, PLSPredict was applied to further investigate the predictive power of the model under study. The results are presented in Table 5.

Table 4: Assessment of Path Relationship

\begin{tabular}{|c|c|c|c|c|c|c|c|c|c|c|}
\hline Path Relationship & Beta & $\begin{array}{l}\text { Standard } \\
\text { Error }\end{array}$ & $t$ Statistics & $p$ Values & $5.00 \%$ & $95.00 \%$ & VIF & $f^{2}$ & $R^{2}$ & $Q^{2}$ \\
\hline PE -> BI & 0.258 & 0.032 & $8.069 * * *$ & 0.000 & 0.206 & 0.312 & 2.595 & 0.152 & 0.831 & 0.692 \\
\hline EE -> BI & 0.221 & 0.034 & $6.454 * * *$ & 0.000 & 0.163 & 0.278 & 2.519 & 0.115 & & \\
\hline SI -> BI & 0.019 & 0.024 & 0.793 & 0.214 & -0.019 & 0.060 & 1.464 & 0.001 & & \\
\hline FC $->$ BI & 0.064 & 0.030 & $2.174^{*}$ & 0.015 & 0.009 & 0.106 & 2.035 & 0.012 & & \\
\hline HM -> BI & 0.099 & 0.033 & $2.971 * *$ & 0.002 & 0.046 & 0.155 & 2.305 & 0.025 & & \\
\hline PV -> BI & 0.123 & 0.025 & $4.943 * * *$ & 0.000 & 0.079 & 0.158 & 1.381 & 0.064 & & \\
\hline HB -> BI & 0.347 & 0.035 & $10.022 * * *$ & 0.000 & 0.294 & 0.405 & 2.266 & 0.315 & & \\
\hline BI -> UE & 0.775 & 0.019 & $40.143 * * *$ & 0.000 & 0.743 & 0.805 & 1.009 & 1.504 & 0.601 & 0.291 \\
\hline Gender*PE -> BI & -0.015 & 0.035 & 0.424 & 0.336 & -0.076 & 0.041 & 2.637 & 0.001 & & \\
\hline Gender*EE -> BI & 0.068 & 0.035 & $1.945^{*}$ & 0.026 & 0.007 & 0.119 & 2.557 & 0.011 & & \\
\hline Gender*SI -> BI & -0.050 & 0.025 & $1.977^{*}$ & 0.024 & -0.093 & -0.010 & 1.469 & 0.010 & & \\
\hline Gender*FC -> BI & 0.003 & 0.030 & 0.117 & 0.454 & -0.044 & 0.051 & 2.052 & 0.000 & & \\
\hline Gender*HM -> BI & 0.072 & 0.031 & $2.272 *$ & 0.012 & 0.024 & 0.129 & 2.282 & 0.013 & & \\
\hline Gender*PV -> BI & 0.047 & 0.023 & $2.092 *$ & 0.018 & 0.009 & 0.083 & 1.386 & 0.010 & & \\
\hline Gender*HB -> BI & -0.084 & 0.037 & $2.256^{*}$ & 0.012 & -0.153 & -0.021 & 2.285 & 0.019 & & \\
\hline Gender*BI -> UE & 0.030 & 0.032 & 0.945 & 0.172 & -0.025 & 0.081 & 1.009 & 0.002 & & \\
\hline
\end{tabular}

Note: $* \mathrm{p}<0.05, * * \mathrm{p}<0.01, * * * \mathrm{p}<0.001$

Table 5: PLSPredict Assessment of Variables

\begin{tabular}{lcccc}
\hline Items & \multicolumn{2}{c}{ PLS-SEM } & LM & PLS-SEM - LM \\
& RMSE & $\boldsymbol{Q}_{\text {predict }}^{2}$ & RMSE & RMSE \\
\hline BI1 & 0.642 & 0.624 & 0.558 & 0.084 \\
BI2 & 0.719 & 0.572 & 0.598 & 0.121 \\
BI3 & 0.691 & 0.617 & 0.593 & 0.098 \\
BI4 & 0.713 & 0.607 & 0.581 & 0.132 \\
UE1 & 1.285 & 0.501 & 1.076 & 0.209 \\
UE3 & 0.803 & 0.310 & 0.759 & 0.044 \\
UE4 & 1.755 & 0.134 & 1.565 & 0.190 \\
UE6 & 2.089 & 0.056 & 1.873 & 0.216 \\
\hline
\end{tabular}

The performance of the PLS-SEM model is compared to the performance of the naïve linear regression (LM) benchmark model. As all $Q_{\text {predict }}^{2}$ values are greater than zero, we can proceed with the comparison of both models. The comparison of predictive power (PLS-SEM - LM) is done using the root mean squared error (RMSE), which accommodates for highly symmetrically distributed prediction errors (Shmueli, 2019). 
When the RMSE statistical values of the PLS-SEM model are compared to naïve LM benchmark models, none of the indicators show that RMSE values of PLS-SEM are less than the RMSE values of the naïve LM benchmark. This suggests the model lacks predictive power and provides room to modify the model to improve its predictive power for mobile Internet adoption intentions (see Figures $2 \& 3$ ).

Figure 2: Importance-Performance Map for Predicting Mobile Internet Adoption Among Female Users in Suburban

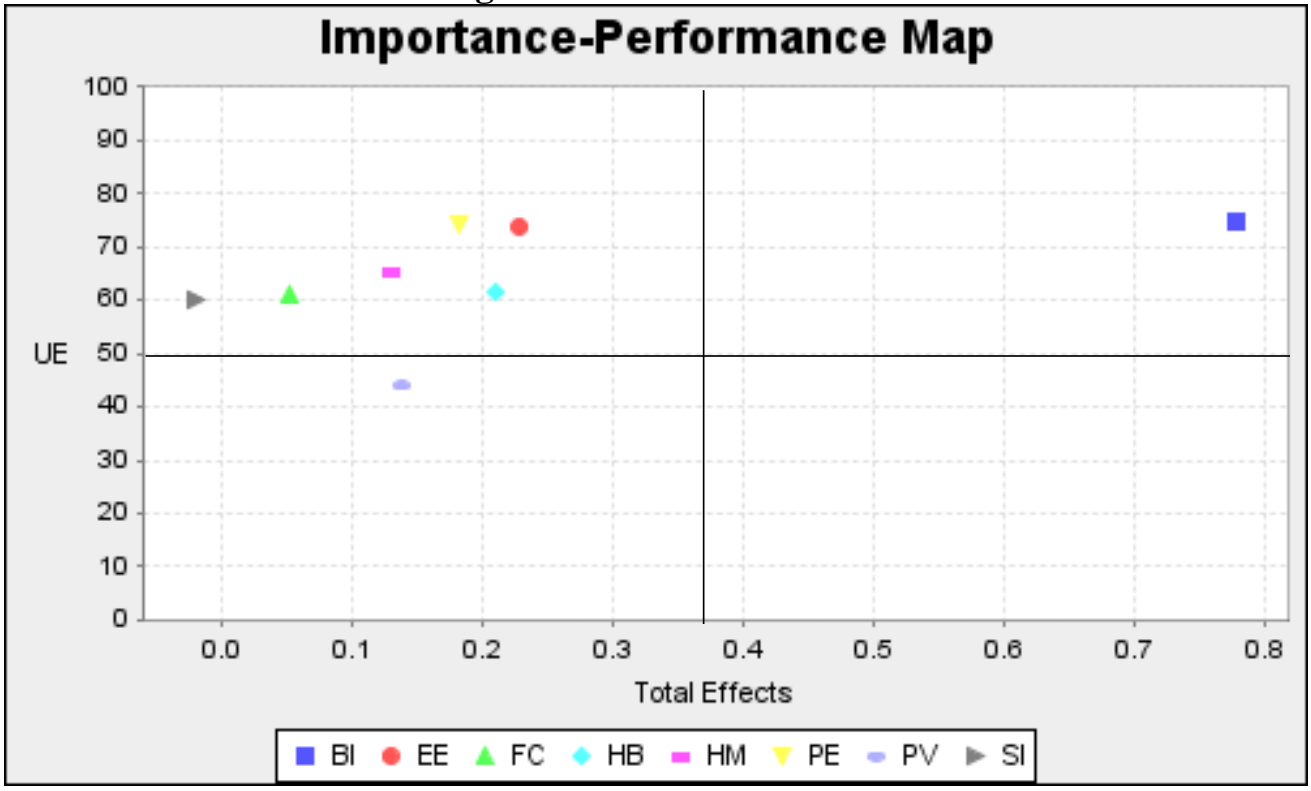

Figure 3: Importance-Performance Map for Predicting Mobile Internet Adoption Among Male Users in Suburban

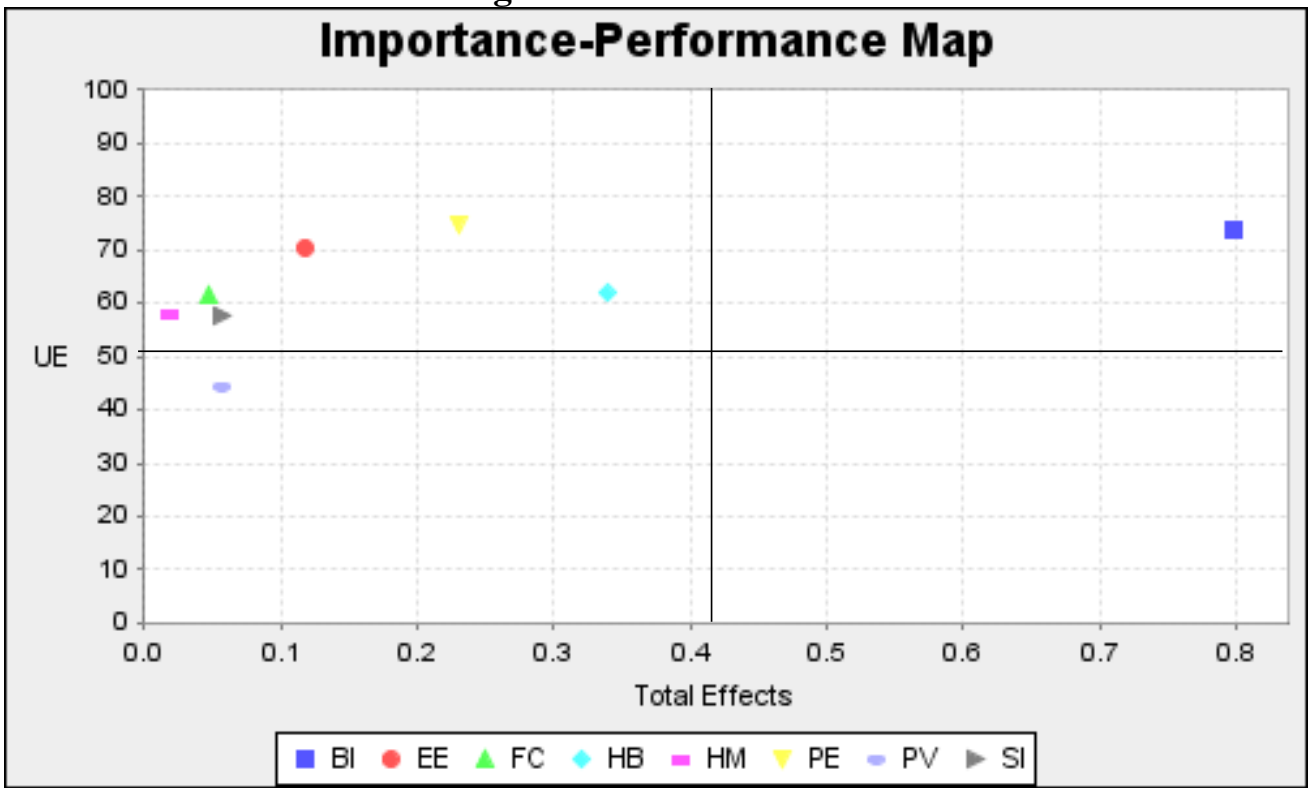


On the other hand, Figure 3 shows the Importance-Performance Map for predicting mobile Internet adoption among male suburban users. All factors except price value need to be enhanced to promote Internet adoption among male users. Hedonic motivation, facilitating condition and social influence are the areas to focus on for awareness creation in addition to effort expectancy, habit, and performance expectancy.

\section{Discussion}

First, the effect of performance expectancy, effort expectancy, social influence, facilitating condition, hedonic motivation, price value, and habit were tested. Based on the findings of this study, performance expectancy has a positive linear relationship with mobile Internet adoption intention. This means that Malaysian suburban users perceived the mobile Internet as useful and enjoyed the relative advantage of increasing their productivity and efficiency. This finding is consistent with those of Wu et al. (2007), Zhou (2011), Madara (2013) and Alwahaishi (2014). Next, effort expectancy is also found to have similar positive linear relationships with mobile Internet adoption intention. This result is also consistent with the findings of Zhou (2011) and Madara (2013) who discovered that the perceived ease of use effect in effort expectancy can significantly influence user satisfaction, which subsequently affects the behavioural intention to use mobile Internet.

Social influence was not found to significantly affect mobile Internet adoption intentions. This is an interesting finding for Malaysian suburban mobile service subscribers since most past researchers such as Park et al. (2007) and Wu et al. (2007) have credited the overpowering influence of word-of-mouth from salient referent groups on an individual's behavioural intention. Furthermore, the most common Internet activities of Malaysian Internet users are text communication and visiting social networking platforms (Malaysian Communications and Multimedia Commission, 2019). However, the number of premises with good broadband connectivity in suburban areas are still lagging behind other areas, which may affect the ability to use text communication and social networking platforms. Thus, the impact of social influence on suburban users is not significant. This is in contrast to the context of Europe and Central Asia, in which mobile social networking is expected to enhance the adoption rate (Kelly, et al., 2017).

In addition, a positive linear relationship exists between facilitating condition and mobile Internet adoption intention. This finding is consistent with Venkatesh et al. (2003) and Park et al. (2007) in that when ease of use criteria of effort expectancy can be satisfied, one will rely less on external support in facilitating mobile Internet usage. Based on the Internet Users Survey 2018, the smartphone is the top device used to access the Internet in Malaysia. Hedonic motivation, on the other hand, is also found to have a significant positive linear relationship with mobile Internet adoption intentions. This shows that Malaysian suburban users emphasise the fun, pleasure and entertainment offered by using mobile Internet as important aspects in affecting their adoption. This finding is also consistent with Childers et al. (2001), Brown and Venkatesh (2005) and Venkatesh et al. (2012) who found that hedonic motivation was a significant determinant of technology acceptance and use in the consumer context. In India, hedonic motivation also implies the consumers' perceived level of 
enjoyment and possesses a significant motivational effect on the behaviour of consumers (Madan \& Yadav, 2018).

Price value is also significant in affecting mobile Internet adoption intention. If the cost and pricing structure is set too high, it can significantly impact adoption. This finding is consistent with Soltani and Gharbi (2008), Kuo et al. (2009), Zhao et al. (2012) and Venkatesh et al. (2012), where price value is a crucial factor to attract consumers. In Europe and Central Asia, two distinctive categories are found, namely low prices and high penetration or high prices and low penetration (Kelly et al., 2017).

The last determinant, habit, is also found to have a positive linear relationship with mobile Internet adoption intentions. This means that suburban users' mobile Internet adoption is very much influenced by habitual criteria as a result of repeated behaviour such as habitual use of social media during commuting will trigger usage in other occasion. Such finding is consistent with Venkatesh et al. (2012) where habit is a significant predictor of behavioural intention.

Behavioural intention is found to be a significant predictor of mobile Internet use behaviour among Malaysian suburban users in which the relationship is positive. Thus, the frequency of usage relies on mobile Internet adoption.

Second, the effect of gender is also incorporated in the testing of the direct relationships between all the determinants and mobile Internet adoption intentions. The effect is identified via the moderating effect of gender and IPMA analysis. From the results, we find that gender does not moderate the relationship between performance expectancy and mobile Internet adoption intention. The finding is inconsistent with Ameen and Willis (2019) where gender demonstrated significantly different effects on behavioural intention. Females may not be aware of the benefits of having Internet access via mobile phones. This may be because females are more family focused than focused on self-fulfilment (Hirschman, 2016).

Gender is found to moderate the relationship between effort expectancy and mobile Internet adoption intention among Malaysian suburban users in such a way that the effect is greater on females. This outcome tallies with the findings of Vankatesh et al. (2012). As females spend more time in house work, they may have less time to access the Internet. If less effort is required in accessing the Internet using their mobile phones, the intention to adopt mobile Internet will be higher. Gender also moderates the relationship between social influence and mobile Internet adoption intention, in which the effect is stronger for females. The finding is identical with the findings of Venkatesh et al. (2012). Females are more likely to be affected by their friends or family, but with reduced effects on mobile Internet adoption. This is probably because their friends or family may encourage them to spend more time with their family rather than on mobile phones. Therefore, the tendency to have Internet access will be less. 
Gender is insignificant in the relationship between facilitating conditions and mobile Internet adoption intentions. The finding is supported by the findings of Ameen and Willis (2019). As females may not aware of the benefits of having Internet access, they may not explore more functions that can be carried out using their phones. Therefore, guidance and training may not be relevant to them.

The relationship between hedonic motivation and mobile Internet adoption intentions is found to be moderated by gender where greater effects are found on females. This is in contrast to the findings of Venkatesh et al. (2012) that greater motivation should be felt by males as they have more tendency to seek novelty and innovativeness. Harsono and Suryana (2014) found that women are more concerned with the pleasure and entertainment offered by social media, but not men. Besides, the relationship between price value and adoption among Malaysian suburban users is also found to be moderated by gender with greater impact on females, which is consistent with Venkatesh et al. (2012). Suburban females have put a higher value on hedonic motivation and thus it is foreseeable that the hedonic benefits allow them to better justify costs and to assign a higher price value than males.

Gender is found to moderate the relationship between habit and behavioural intention in such a way that females have more impact compared to males. Thus, the result is inconsistent with Venkatesh et al. (2012) who found that the impact from males is greater. This may be because mobile phones are only used at certain times or to perform certain tasks. The habit may not critically contribute to mobile Internet adoption. Lastly, the gender effect is not found to be moderating the relationship between mobile Internet adoption and use behaviour.

Based on the IPMA, females assign greater importance to price value compared to males. The strategy to create price value is a continuous effort that needs to be made by mobile Internet service providers. This research also found a lack of awareness of all determinants of mobile Internet adoption (except price value) among both males and females. However, the weightages for males and females in certain factors are different. For instance, more focus should be put on social influence for females while more weight should be assigned to create awareness of hedonic motivation, facilitating condition, and social influence among males. The strategies of awareness creation will be discussed in the following section.

\section{Managerial Implications}

This study contributes to the literature of the UTAUT2 model by emphasizing the role of gender in suburban areas in Malaysia in terms of Internet use. There are approximately 1.7 billion females who are not connected to the Internet in low income as well as middle income countries (Kelly et al., 2017). This study provides some insights of the gender effect in the UTAUT2 model. The gender effect is included to test the relationships between each of every determinant and mobile Internet adoption, as well as the relationship between mobile Internet adoption and use behaviour. Furthermore, in a study incorporated Indonesia, Myanmar, the Philippines, and Vietnam, some countries were found to display low technology use even in the urban areas (Lai, Chib \& Ling, 2015). In Malaysia, the discussion of suburban and rural area 
development are tied together. There is a lack of study specifically for suburban areas in Malaysia and therefore suburban area is chosen for this study.

As performance expectancy is related to mobile Internet adoption intention, awareness creation among users (regardless of gender) on the benefits or usefulness of mobile Internet access is important. The online activities that can be carried out on the Internet need to be conveyed to users, including searching, mobile learning, entertainment, social networking, bill payment, mobile commerce and others. In other Asian contexts such as Iraq, awareness creation is also vital. However, gender has impact on performance expectancy, in which the willingness to use smartphones and their applications depends on how well females were informed regarding the benefits of smart phones (Ameen \& Willis, 2019).

The mobile Internet service providers also need to create awareness of the effort required to use mobile technology, by focusing on female users. As females are often occupied with house work and other tasks in the home (Ferrant, Pesando \& Nowacka, 2014), less effort is required to use mobile technology and beneficial tasks performed via mobile will enhance mobile Internet adoption. For instance, if female users are aware of the QR code and mobile banking technologies, they may find payment for utilities bills is easy. Therefore, marketing activities can be designed to educate users, especially female users, on the technology available via mobile phones. Under effort expectancy, ease of use can be one of the criteria and to make device functions simple is critical, as suggested by Megadewandanu (2016) in Indonesia.

As social influence is not related to mobile Internet adoption intention, awareness can be created by mobile Internet service providers in the form of competitions that involve family members and friends. Besides, mobile Internet service providers can also offer family packages for network and data plans. This will encourage family usage and thus increase mobile Internet adoption. The competitions to create awareness of mobile technology can be targeted at mothers, to motivate females to use mobile phones in daily life, which may subsequently lead to higher mobile Internet adoption.

External help, support, training and others are critical facilitating conditions (Venkatesh et al., 2008). Thus, to enhance mobile Internet adoption intentions, awareness needs to be created about external help, support, training and others to provide guidance to users on connectivity, use of technology, mobile functions and others.

Although habit can lead to higher mobile Internet adoption intentions, the impact is less for females. Therefore, more marketing efforts are needed to strengthen stored intentions and their links to behaviour, especially for female users. For instance, when a mobile Internet application is introduced, advertisements should emphasize the variety of scenarios the application or service could be used in, such as sharing experience with friends, taking photos to share with the boss or colleagues while on official duty, voice and video conferencing while on-the-move or in some extreme locations on mountain peaks or far rural areas, and so on to help to strengthen the likelihood that stored intentions will be translated into different usage contexts. 
In terms of hedonic motivation and price value, the perceived benefits of mobile Internet services should be balanced with costs. As with India, if a consumer knows the cost is low, then the behavioural intention to adopt will be higher (Madan \& Yadav, 2018). High cost of devices and import duties compared to income levels are the obstacles lead to low smartphone adoption in Europe and Central Asia (Kelly et al., 2017). Even though services can be promoted based on fun and enjoyment of hedonic motivation, if the pricing is too high, the hedonic benefits of using the services may not be high enough to justify the price. As female users may view price value as slightly more important than male users, male users may need more awareness in terms of hedonic motivation, and therefore service providers should optimize pricing based on balanced utilization, hedonic and price value to maximize profit.

\section{Implications for Asian Business Context}

The managerial implications derived from the findings of this study for domestic mobile Internet service providers is also consistent with the trend of Asian development. Mobile phone usage is expanding in Emerging Asia and there is approximate 80 percent and two-third of Internet users utilize smartphones to access Internet in China and Association of Southeast Asian Nations (ASEAN), respectively (OECD, 2018). This development may boost e-commerce growth in Asia (OECD, 2018). Global mobile payment market is projected to expend to USD 1 trillion in 2019 and smartphone access accounts for approximate one-third of B2C revenues (OECD, 2018). Investigation on the determinants of mobile internet adoption intention enables authorities in Malaysia as well as mobile Internet service providers to close the gap between Malaysia and Asia regarding the development in ecommerce and mobile payment. This can only be achieved with more users adopt to the Internet service. Thus, the awareness creation in relation to the determinants will be critical to increase the mobile Internet adoption. In addition, the availability of Internet infrastructure will be an important area to be taken care by local authorities and mobile Internet service providers to meet the increased demand for mobile Internet. Therefore, development of suburban areas is inclusive in the broadband plan in Malaysia and the context of this study is suburban area.

Furthermore, another implication from this study is the effect of gender. International Telecommunication Union revealed that global women generally have less access and use of information and telecommunication technologies (OECD, 2019). In 2017, the gap between males and females in terms of use and access is 17 percent in Asia and Pacific regions (OECD, 2019). When digital tools are used for professional functions, the unpaid work hours by women can be reduced and therefore women can have accelerated flexibility in work duration and location due to the emerging of digital economy (OECD, 2019). To reduce the digital gap, awareness needs to be created for females so that they can also benefit from the wave of digital development such as to work at home or to work anytime. Due to the flexibility, women entrepreneurs can be one of the areas of contribution by females. Therefore, the factors such as effort expectancy, habit, and price value can be emphasized for females to increase the mobile Internet adoption. 


\section{Further Research Directions}

This study covers the investigation of the predictors influencing the mobile Internet adoption and use behaviour for suburban mobile users in Malaysia. Six predictors, namely performance expectancy, effort expectancy, facilitating conditions, hedonic motivation, price value and habit are important in enhancing mobile Internet adoption and usage. However, social influence is not significant enough to predict intention and use behaviour, which may be due to the degree of usage of social media by suburban residents. Females react differently to effort expectancy, hedonic motivation and price value, as tasks performed by females are different compared to males. As UTAUT2 was adopted for the investigation, there may be some other factors such as the performance of broadband which can be included in the study in future. The rural areas are excluded in this study due to accessibility issues, which can be considered in future research.

\section{Acknowledgement}

This working paper has been presented at 2019 MAGScholar Conference in Business, Marketing \& Tourism at Macau University of Science and Technology on June 25-26, 2019. The authors would also like to acknowledge UCSI University for the conference funding (No: CFR-2019-000054, Code: CONF-INT-FOBIS/SWK-5).

\section{References}

Ajzen, I., Fishbein, M., (1975), Belief, attitude, intention and behaviour: An introduction to theory and research, Addison-Wesley, Reading.

Al-Qeisi, K. I., (2009), "Analysing the use of UTAUT model in explaining an online behaviour: Internet banking adoption", Brunel University Brunel Business School PhD Theses, Marketing Brunel Business School London, London.

Alwahaishi, S., (2014), "Determinants of consumer acceptance of mobile Internet: An empirical study", The International Conference on Digital Information, Networking and Wireless Communications, pp. 9-19.

Ameen, N., Willis, R., (2019), "Towards closing the gender gap in Iraq: Understanding gender differences in smartphone adoption and use", Information Technology for Development, vol. 25, no. 4, pp. 660-685.

Arenas-Gaitán, J., Peral-Peral, B., \& Ramón-Jerónimo, M., (2015), "Elderly and internet banking: An application of UTAUT2", Journal of Internet Banking and Commerce, vol. 20, no. 1, pp. 1-23.

Ariff, S. U., (2019), "Internet connectivity may soon be listed under utilities", Retrieved from https://www.nst.com.my/news/government-public-policy/2019/04/481895/internetconnectivity-may-soon-be-listed-under

Baptista, G., \& Oliveira, T., (2015), "Understanding mobile banking: The unified theory of acceptance and use of technology combined with cultural moderators", Computers in Human Behaviour, vol. 50, pp.418-430.

Bandura, A., (1986), Social foundations of thought and action: A social cognitive theory, Prentice Hall, New Jersey.

Boksberger, P. E., \& Melsen, L., (2011), "Perceived value: A critical examination of definitions, concepts and measures for the service industry", Journal of Services Marketing, vol. 25, no. 3, pp. 229-240. 
Brown, S. A., \& Venkatesh, V., (2005), "Model of adoption of technology in the household: A baseline model test and extension incorporating household life cycle", MIS Quarterly, vol. 29, no. 4, pp. 399-426.

Cahill, F., \& Ryan, E., (2019), Women and cities, Retrieved from http://citiesprogramme .org/focus-area/womens-empowerment-and-gender-equality/

Casey, T., \& Wilson, E., (2012), "Predicting uptake of technology innovations in online family dispute resolution services: An application and extension of the UTAUT", Computer in Human Behaviour, vol. 28, no. 6, pp. 2034-2045.

Childers, T. L., Carr, C. L., Peck, J., \& Carson, S., (2001), "Hedonic and utilitarian motivations for online retail shopping behaviour", Journal of retailing, vol. 77, no. 4, pp. 511-535.

Chong, A. Y. L., (2013), "Mobile commerce usage activities: The roles of demographic and motivation variables", Technological Forecasting and Social Change, vol. 80, no. 7, pp. 1350-1359.

Chopdar, P. K., Korfiatis, N., Sivakumar, V. J., \& Lytras, M. D., (2018), "Mobile shopping apps adoption and perceived risks: A cross-country perspective utilizing the unified theory of acceptance and use of technology", Computers in Human Behaviour, vol. 86, pp.109-128.

Cisco, (2016), Cisco visual networking index: Global mobile data traffic forecast update, 2015-2020 (FLGD 12725 02/16), Cisco System, Inc. Americas Headquarters, San Jose.

Cohen, J., (1988), Statistical power analysis for the behavioural sciences, Lawrence Erlbaum Associates, New York.

Davis, F. D., (1989), "Perceived usefulness, perceived ease of use, and user acceptance of information technology", MIS Quarterly, vol. 13, no. 3, pp. 319-339.

Duarte, P., \& Pinho, J. C., (2019), "A mixed methods UTAUT2-based approach to assess mobile health adoption", Journal of Business Research, Vol. 102, pp.140-150.

Dwivedi, Y. K., Shareef, M. A., Simintiras, A. C., Lal, B., \& Weerakkody, V., (2016), “A generalised adoption model for services: A cross-country comparison of mobile health (m-health)", Government Information Quarterly, vol. 33, no. 1, pp. 174-187.

Dwivedi, Y. K., Rana, N. P., Janssen, M., Lal, B., Williams, M. D., \& Clement, M., (2017a), "An empirical validation of a unified model of electronic government adoption (UMEGA)", Government Information quarterly, vol. 34, no. 2, pp. 211-230.

Dwivedi, Y. K., Rana, N. P., Jeyaraj, A., Clement, M., \& Williams, M. D., (2017b), "Reexamining the unified theory of acceptance and use of technology (UTAUT): Towards a revised theoretical model", Information Systems Frontiers, vol. 21, no. 3, pp.719-734.

Economic Planning Unit, (2015), Eleventh Malaysia Plan 2016-2020: Anchoring growth on people, Prime Minister's Department, Putrajaya, Malaysia.

Evan, A., (2013), Who invented the Internet? Ask history, Retrieved from http://www.histo ry.com/news/ask-history/who-invented-the-internet

Ferrant, G., Pesando, L. M., \& Nowacka, K., (2014), "Unpaid Care Work: The missing link in the analysis of gender gaps in labour outcomes", OECD Development Centre, pp. 1-12.

GSMA Intelligence, (2015), The mobile economy 2015, GSMA Head Office, London.

GSM Association, (2016), GSMA mobile connectivity index web tool, GSMA intelligence, Retrieved from http://www.mobileconnectivityindex.com

Gupta, A., Dogra, N., \& George, B., (2018), "What determines tourist adoption of smartphone apps? An analysis based on the UTAUT-2 framework", Journal of Hospitality and Tourism Technology, vol. 9, no. 1, pp. 50-64.

Hair, J. F., Hult, G. T. M., Ringle, C. M., \& Sarstedt, M., (2017), A primer on Partial Least Squares-Structural Equation Modeling (PLS-SEM), Sage Publications, London.

Harsono, I. L. D., \& Suryana, L. A., (2014), "Factors affecting the use behaviour of social media using UTAUT2 model", Proceedings of the First Asia-Pacific Conference on Global Business, Economics, Finance and Social Sciences, pp. 1-14.

Henseler, J., Ringle, C. M., \& Sarstedt, M., (2015), "A new criterion for assessing discriminant validity in variance-based structural equation modelling", Journal of the Academy of Marketing Science, vol. 43, no. 1, pp. 115-135. 
Herrero, Á., San Martín, H., \& García de los Salmones, M., (2017), "Explaining the adoption of social networks sites for sharing user-generated content: A revision of the UTAUT2", Computers in Human Behaviour, vol. 71, pp. 209-217.

Hirschman, C., (2016), "Gender, the status of women, and family structure in Malaysia", Malaysian Journal of Economic Studies, vol. 53, no. 1, pp. 33-50.

Hsu, C. L., \& Lu, H. P., (2004), "Why do people play online games? An extended TAM with social influences and flow experience", Information and Management, vol. 41, no. 7, pp. 853-868.

Huang, C. Y., \& Kao, Y. S., (2015), "UTAUT2 based predictions of factors influencing the technology acceptance of phablets by DNP", Mathematical Problems in Engineering, vol. 2015, no. 1, pp. 1-23.

Jasperson, J., Carter, P. E., \& Zmud, R. W., (2005), “A comprehensive conceptualization of the post-adoptive behaviours associated with IT-enabled work systems", MIS Quarterly, vol. 29, no. 3, pp. 525-557.

Jeng, D. J. F., \& Tzeng, G. H., (2012), "Social influence on the use of clinical decision support systems: Revisiting the unified theory of acceptance and use of technology by the fuzzy DEMATEL technique", Computer and Industrial Engineering, vol. 62, no. 3, pp. 819-828.

Jiang, P. J., (2009), "Consumer adoption of mobile internet services: An exploratory study", Journal of Promotion Management, vol. 15, no. 3, pp. 418-454.

Jorge, A. G., Begona, P. P., \& Maria A. R. J., (2015), "Elderly and internet banking: An application of UTAUT2", Journal of Internet Banking and Commerce, vol. 20, no. 1, pp. 1-23.

Kelly, T., Liaplina, A., Tan, S. W., \& Winkler, H., (2017), Reaping digital dividends: Leveraging the Internet for development in Europe and Central Asia, The World Bank, Washington.

Kijsanayotin, B., Pannarunothai, S., Speedie, S. M., (2009), "Factors influencing health information technology adoption in Thailand's community health centres: Applying the UTAUT model", International Journal of Medical Informatics, vol. 78, no. 6, pp. 404416.

Kim, H. W., Chan, H. C., \& Gupta, S., (2007), "Value-based adoption of mobile internet: An empirical investigation", Decision Support Systems, vol. 43, no. 1, pp. 111-126.

Kim, S., Littrell, M. A., (1999), "Predicting souvenir purchase intentions", Journal of Travel Research, vol. 38, pp. 153-162.

Kim, S. S., \& Malhotra, N. K., (2005), "A longitudinal model of continued IS use: An integrative view of four mechanisms underlying post-adoption phenomena", Management Science, vol. 51, no. 5, pp. 741-755.

Kim, S. S., Malhotra, N. K., \& Narasimhan, S., (2005), "Two competing perspectives on automatic use: A theoretical and empirical comparison", Information Systems Research, vol. 16, no. 4, pp. 418-432.

Kuo, Y. F., Wu, C. M., \& Deng, W. J., (2009), “The relationships among service quality, perceived value, customer satisfaction, and post-purchase intention in mobile valueadded services", Computer in Human Behaviour, vol. 25, no. 4, pp. 887-896.

Lai, C.H., Chin, A., \& Ling, R., (2015), State of the use of mobile technologies for disaster preparedness in South East Asia, Nanyang Technological University, Singapore.

Limayem, M., Hirt, S. G., \& Cheung, C. M. K., (2007), "How habit limits the predictive power of intentions: The case of IS continuance", MIS Quarterly, vol. 31, no. 4, pp. 705-737.

Macedo, I. M., (2017), "Predicting the acceptance and use of information and communication technology by older adults: An empirical examination of the revised UTAUT2", Computers in Human Behaviour, vol. 75, pp. 935-948.

Madara, F., (2013), "Mobile technologies and services development impact on mobile internet usage in Latvia", Procedia Computer Science, vol. 26, pp. 41-50. 
Madan, K., \& Yadav, R., (2018), "Understanding and predicting antecedents of mobile shopping adoption: A developing country perspective", Asia Pacific Journal of Marketing and Logistics, vol. 30, no. 1, pp.139-162.

Madden, T. J., Ellen, P. S., \& Ajzen, I., (1992), "A comparison of the theory of planned behaviour and the theory of reasoned action", Personality and Social Psychology Bulletin, vol. 18, no.1, pp. 3-9.

Magni, M., Taylor, M. S., \& Vankatesh, V., (2010), “To play or not to play: A cross-temporal investigation using hedonic and instrumental perspectives to explain user intentions to explore a technology", International Journal of Human Computer Studies, vol. 68, no. 9, pp. 572-588.

Malaysian Communications and Multimedia Commission, (2018), Industry performance report 2017, Malaysian Communications and Multimedia Commission, Cyberjaya.

Malaysian Communications and Multimedia Commission, (2019), Industry performance report 2018, Malaysian Communications and Multimedia Commission, Cyberjaya.

Malaysian Communications and Multimedia Commission, (2018), Internet users survey 2018, Malaysian Communications and Multimedia Commission, Cyberjaya.

Megadewandanu, S., (2016), "Exploring mobile wallet adoption in Indonesia using UTAUT2: An approach from consumer perspective", 2016 2nd International Conference on Science and Technology-Computer (ICST), pp. 11-16.

Merhi, M., Hone, K., \& Tarhini, A., (2019), "A cross-cultural study of the intention to use mobile banking between Lebanese and British consumers: Extending UTAUT2 with security, privacy and trust", Technology in Society, vol. 59, pp. 1-12.

Moon, Y. J., \& Hwang, Y. H., (2016), A study of effects of UTAUT-based factors on acceptance of smart health care services, In Advanced multimedia and ubiquitous engineering, Springer, Berlin.

OECD, (2018), Economic outlook for Southeast Asia, China and India 2018 - update: promoting opportunities in e-commerce, OECD Publishing, Paris.

OECD, (2019), Southeast Asia going digital: Connecting SMEs, OECD, Paris.

Oliver, R. L., (1980), "A cognitive model of the antecedents and consequence of satisfaction decisions", Journal of Marketing Research, vol. 17, no. 4, pp. 460-469.

Park, J. K., Yang, S. J., \& Xinran, L., (2007), “Adoption of mobile technologies for Chinese consumers", Journal of Electronic Commerce Research, vol. 8, no. 3, pp. 196-206.

Performance Management and Delivery Unit, (2010), economic transformation programme: A roadmap for Malaysia, Prime Minister's Department, Putrajaya, Malaysia.

Petrick, J. F., (2002), "Development of a multi-dimensional scale for measuring the perceived value of a service", Journal of Leisure Research, vol. 34, no. 2, pp. 119-134.

Ramírez-Correa, P., Rondán-Cataluña, F. J., Arenas-Gaitán, J., \& Martín-Velicia, F., (2019), "Analysing the acceptation of online games in mobile devices: An application of UTAUT2", Journal of Retailing and Consumer Services, vol. 50, pp. 85-93.

Ravangard, R., Kazemi, Z., Abbasali, S. Z., Sharifian, R., \& Monem, H., (2017), "Development of the UTAUT2 model to measure the acceptance of medical laboratory portals by patients in Shiraz", Electronic Physician, vol. 9, no. 2, pp. 3862-3869.

Rofiei, R., Tawil, N. M., Kosman, K. A., \& Che-Ani, A. I., (2016), "Understanding the people's needs of living in city: Scenario in Malaysia", Journal of Engineering Science and Technology, vol. 11, no. 5, pp. 704-713.

Rogers, E., (1962), Diffusion of innovation, Free Press, New York.

Sahari, Z., (2015), Limit urban sprawl, Retrieved from https://www.thestar.com.my/metro/vie ws/2015/01/27/limit-urban-sprawl-time-to-start-greening-our-cities-for-the-future.

Sivathanu, B., (2019), "Adoption of digital payment systems in the era of demonetization in India: An empirical study", Journal of Science and Technology Policy Management, vol. 10, no. 1, pp. 143-171.

Shaw, N., \& Sergueeva, K., (2019), "The non-monetary benefits of mobile commerce: Extending UTAUT2 with perceived value", International Journal of Information Management, vol. 45, pp. 44-55. 
Shmueli, G., (2019), "Predictive model assessment in PLS-SEM: Guidelines for using PLSpredict", European Journal of Marketing, vol. 53, no. 11, pp. 2322-2347.

Soltani, I., \& Gharbi, J., (2008), "Determinants and consequences of the website perceived value", Journal of Internet Banking and Commerce, vol.13, no. 1, pp. 1-13.

Statista, (2019), Smartphone penetration rate as share of the population in Malaysia 2017 to $2023^{*}$, Retrieved from https://www.statista.com/statistics/625418/smartphone-userpenetration-in-malaysia/

Susan, G., (2013), The history and evolution of the internet, media, and news in 5 infographics, Retrieved from http://aci.info/2013/10/24/the-history-and-evolution-ofthe-internet-media-and -news-in-5-infographics/

Tamilmani, K., Rana, N. P., Prakasam, N., \& Dwivedi, Y. K., (2019), "The battle of brain vs. heart: A literature review and meta-analysis of "hedonic motivation" use in UTAUT2", International Journal of Information Management, vol. 46, pp. 222-235.

The Sun Daily, (2019), Malaysia's digital economy contributes $18.5 \%$ to GDP in 2018, Retrieved from https://www.thesundaily.my/business/malaysia-s-digital-economy-contr ibutes-18-5-to-gdp-in-2018-JK1491649

Teo, T. S. H., Lim, V. K. G., \& Lai, R. Y. C., (1999), "Intrinsic and extrinsic motivation in Internet usage", Omega, vol. 27, no. 1, pp. 25-37.

Thompson, R. L., Higgins, C. A., \& Howell, J. M., (1991), "Personal computing: Toward a conceptual model of utilization", MIS Quarterly, vol. 15, no. 1, pp. 125-143.

Venkatesh, V., Morris, M., Davis, G., \& Davis, F., (2003), "User acceptance of information technology: Toward a unified view", MIS Quarterly, vol. 27, no. 3, pp. 425-478.

Venkatesh, V., Thong, J. Y-L., Xu, X., (2012), "Consumer acceptance and use of information technology: Extending the Unified Theory of Acceptance and Use of Technology", MIS Quarterly, vol. 36, no. 1, pp. 157-178.

Venkatesh, V., Brown, S. A., Maruping, L. M., \& Bala, H., (2008), "Predicting different conceptualizations of system USE: The competing roles of behavioural intention, facilitating conditions, and behavioural expectation”, MIS Quarterly, vol. 32, no. 3, pp. 483-502.

Wang, H. Y., \& Wang, S. H., (2010), "Predicting mobile hotel reservation adoption: Insight from a perceived value standpoint", International Journal of Hospitality Management, vol. 29, no. 4, pp. 598-608.

Webb, T. L., Sheeran, P., \& Luszczynska, A., (2009), "Planning to break unwanted habits: Habit strength moderates implementation intention effects on behaviour changes", British Journal of Social Psychology, vol. 48, no. 3, pp. 507-523.

Wu, Y. L., Tao, Y. H., \& Yang, P. C., (2007), "Using UTAUT to explore the behaviour of 3G mobile communication users", IEEE International Conference on Industrial Engineering and Engineering Management, vol. 2, no. 4, pp. 199-203.

Zeithaml, V. A., (1988), "Consumer perceptions of price, quality and value: A means-end model and synthesis of evidence", Journal of Marketing, vol. 52, no. 3, pp. 2-22.

Zhao, L., Lu, Y., Zhang, L., \& Chau, P. Y. K., (2012), "Assessing the effects of service quality and justice on customer satisfaction and the continuance intention of mobile value-added services: An empirical test of a multidimensional model", Decision Support Systems, vol. 52, no. 3, pp. 645-656.

Zhou, T., (2011), "Understanding mobile Internet continuance usage from the perspectives of UTAUT and flow", Information Development, vol. 27, no. 3, pp. 207-218. 